\title{
Erratum to: Vitamin D Status and Bone Mineral Density Changes During Alendronate Treatment in Postmenopausal Osteoporosis
}

\author{
Christian Roux $\cdot$ Neil Binkley $\cdot$ Steven Boonen - Douglas P. Kiel • \\ Stuart H. Ralston · Jean-Yves Reginster • Annpey Pong • \\ Elizabeth Rosenberg • Arthur Santora $\cdot$ FOCUS-D Investigators
}

Published online: 15 September 2013

(C) Springer Science+Business Media New York 2013

Erratum to: Calcif Tissue Int

DOI 10.1007/s00223-013-9763-1

Unfortunately the name of sixth author (Jean-Yves Reginster) was spelled incorrectly in the original publication. It is corrected in this erratum.

The online version of the original article can be found under doi:10.1007/s00223-013-9763-1.

C. Roux $(\square)$

Paris Descartes University, Paris, France

e-mail: christian.roux@cch.aphp.fr

N. Binkley

University of Wisconsin, Madison, WI, USA

S. Boonen

Center for Metabolic Bone Disease, Leuven, Belgium

D. P. Kiel

Institute for Aging Research, Hebrew SeniorLife and Harvard

Medical School, Boston, MA, USA

\section{S. H. Ralston}

Institute of Genetics and Molecular Medicine, Western General

Hospital, University of Edinburgh, Edinburgh, UK

J.-Y. Reginster

University of Liege, Liege, Belgium

A. Pong $\cdot$ E. Rosenberg $\cdot$ A. Santora

Merck Sharp and Dohme, Whitehouse Station, NJ, USA 